\title{
Obtaining a black pericarp and improved aroma using genetic resources from Leum Pua rice
}

\author{
Rattikarn Kerdphol $^{\mathrm{a}, \mathrm{b}}$, Tanee Sreewongchai ${ }^{\mathrm{a}, *}$, Prapa Sripichitt $^{\mathrm{a}}$, Saovaluck Uckarach ${ }^{\mathrm{a}}$, \\ Fisseha Worede ${ }^{c}$ \\ a Department of Agronomy, Faculty of Agriculture, Kasetsart University, Bangkok 10900 Thailand \\ b Centre for Advanced Studies for Agriculture and Food, \\ Kasetsart University Institute for Advanced Studies, Kasetsart University, Bangkok 10900 Thailand \\ c Amhara Regional Agricultural Research Institute, Sirinka Agricultural Research Centre Bahir Dar, \\ Ethiopia
}

*Corresponding author, e-mail: taneesree@yahoo.com

Received 27 Sep 2014

Accepted 28 May 2015

\begin{abstract}
Leum Pua, a glutinous rice variety with black pericarp, contains anthocyanin compounds capable of reducing cancer risk. The cooked Leum Pua rice is soft, aromatic, and tasty, but the plant is tall, vulnerable to lodging, and of low yield. This study reports a new rice line carrying the non-glutinous and semi-dwarf traits from IR64, with the aromatic and black pericarp characteristics of Leum Pua. A cross between Leum Pua and IR64 was made to produce $\mathrm{F}_{1}$ progenies and $87 \mathrm{BC}_{1} \mathrm{~F}_{1}$ plants were developed by backcrossing the $\mathrm{F}_{1}$ with IR64. DNA markers Naro1 and Glu_6 were used to select for aroma and non-glutinous traits, respectively. The black pericarp and semi-dwarf traits were selected by visual observation. From the 87 plants of the $\mathrm{BC}_{1} \mathrm{~F}_{1}$ population, 43 plants were selected for aroma, out of which 4 had black pericarp. All these plants were backcrossed to IR64 to produce a $\mathrm{BC}_{2} \mathrm{~F}_{1}$ population. A total of $55 \mathrm{BC}_{2} \mathrm{~F}_{1}$ plants were selected by DNA markers and visual observation, and only 1 plant for aroma and black pericarp was selected. Then 46 plants of the $\mathrm{BC}_{2} \mathrm{~F}_{2}$ population were obtained by selfing of the $\mathrm{BC}_{2} \mathrm{~F}_{1}$ population. The nonglutinous and semi-dwarf traits were maintained by backcrossing. Finally, 6 plants having semi-dwarf, non-glutinous, black pericarp, and aromatic traits were selected. These rice lines are candidates for new rice lines with higher yield potential than the Leum Pua rice variety.
\end{abstract}

KEYWORDS: modified backcross method, non-glutinous rice

\section{INTRODUCTION}

As consumption of healthy foods has increased in Thailand, rice production should focus on nutritionally high quality rice based on consumers' demand. The Leum Pua glutinous rice variety has black pericarp of high nutritional quality, as it contains antioxidant anthocyanins that reduce cancer risk ${ }^{1}$. The cooked Leum Pua rice is soft, aromatic, and tasty. The Leum Pua rice variety however has the disadvantages of low grain yield and photoperiod sensitivity. It can be grown only once a year during rainy season and its tall plant is prone to lodging decreasing the yield. Moreover, it is susceptible to diseases and insects such as blast, bacterial leaf blight, and brown plant hopper ${ }^{2}$.

IR64 rice variety has some important traits. It is non-glutinous, photoperiod insensitive, semidwarf, and resistant to diseases and insects. In
Thailand, it is used as important germplasm for rice breeding. One of the important characteristics for good cooking quality is aroma. Aromatic rice is preferred by consumers and has a premium price in market. Aroma is due to 2-acetyl-1-pyrroline or $2 \mathrm{AP}$ present in the endosperm ${ }^{3}$. The aromatic trait is controlled by the recessive badh gene located on chromosome $8^{4}$. The non-glutinous trait is due to the dominant waxy gene on chromosome $6^{5}$. The pigments in rice accumulate in the pericarp layer only. The black pericarp trait is caused by dominant gene with maternal effect ${ }^{6}$. The semi-dwarf gene in rice, which is called "Green Revolution Gene", is controlled by the recessive $s d 1$ gene $^{7}$. The objective of this study was to improve IR64 rice by introgressing the aromatic and black pericarp characteristics traits from Leum Pua rice by backcrossing while maintaining the non-glutinous and semi-dwarf traits of IR64 rice. 


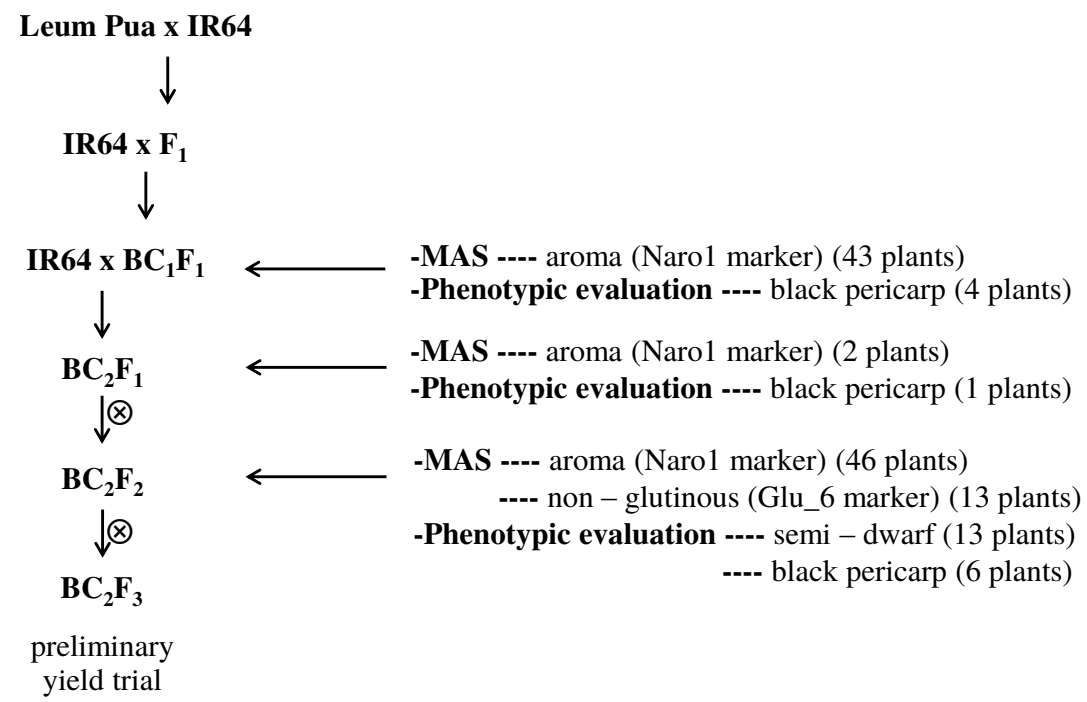

Fig. 1 Markers and phenotypes assisted backcrossing scheme.

\section{MATERIALS AND METHODS}

\section{Plant materials and crossing scheme}

Leum Pua rice variety was used as the donor parent and IR64 was used as the recurrent parent. At flowering stage, emasculation was performed and crossing between Leum Pua and IR64 was done. One month after hybridization, seeds were harvested and used for the next cycle planting. Backcrossing was done with IR64 until $\mathrm{BC}_{2} \mathrm{~F}_{1}$ generation, and then after, the lines were self-pollinated until $\mathrm{BC}_{2} \mathrm{~F}_{3}$ generation (Fig. 1).

\section{Phenotypic evaluation}

Phenotypic evaluation for black pericarp was done in $\mathrm{BC}_{1} \mathrm{~F}_{1}$ until $\mathrm{BC}_{2} \mathrm{~F}_{2}$ populations by observing the pigment of the seeds of individual plants. Selection for semi-dwarf trait was done at $\mathrm{BC}_{2} \mathrm{~F}_{2}$ by measuring plant height and by comparing the individual plants with Leum Pua and IR64 rice varieties in the paddy field (Fig. 1).

\section{DNA extraction and trait selection}

Polymerase Chain Reaction (PCR) was run by using Phire Plant Direct PCR Kit; this was designed to amplify DNA directly from plant samples. No DNA extraction was required prior to the PCR. After PCR was completed, the polymorphism of the PCR products was detected by $\mathrm{AgNO}_{3}$ staining after electrophoresis on $6 \%$ polyacrylamide gels ${ }^{8}$. Marker assisted selection (MAS) was employed at $\mathrm{BC}_{1} \mathrm{~F}_{1}$ and $\mathrm{BC}_{2} \mathrm{~F}_{1}$ generations (Fig. 2) to select for heterozygous individual plants, and at $\mathrm{BC}_{2} \mathrm{~F}_{2}$ genera-

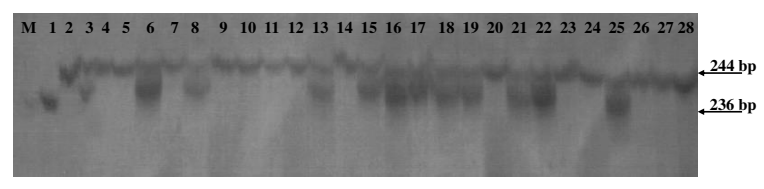

Fig. 2 Genotypic evaluation of $\mathrm{BC}_{1} \mathrm{~F}_{1}$ and $\mathrm{BC}_{2} \mathrm{~F}_{1}$ population using Naro1 marker; $\mathrm{M}=$ Marker; $1=$ Leum Pua; $2=\mathrm{IR} 64 ; 3-28=\mathrm{BC}_{1} \mathrm{~F}_{1}$ and $\mathrm{BC}_{2} \mathrm{~F}_{1}$ individuals.

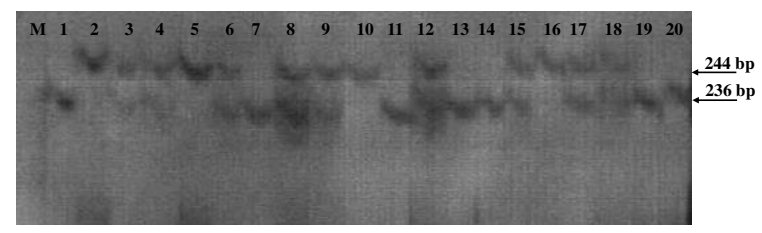

Fig. 3 Genotypic evaluation of $\mathrm{BC}_{2} \mathrm{~F}_{2}$ population using Naro1 marker; $\mathrm{M}=$ Marker; $1=$ Leum Pua; $2=$ IR64; 3$20=\mathrm{BC}_{2} \mathrm{~F}_{2}$ individuals.

tion (Fig. 3) to select for homozygous individuals for aroma by using Naro1 marker ${ }^{9}$. The MAS for non-glutinous trait was done at $\mathrm{BC}_{2} \mathrm{~F}_{2}$ generation (Fig. 4) targeting for homozygous genotype by Glu_6 marker ${ }^{10}$.

\section{RESULTS}

\section{Foreground trait selection}

The foreground traits are aromatic and black pericarp from Leum Pua variety. A total of $87 \mathrm{BC}_{1} \mathrm{~F}_{1}$ individual plants were generated by backcrossing the $\mathrm{F}_{1}$ plants with IR64. The 87 plants were screened for aroma by using Naro1 marker. At 


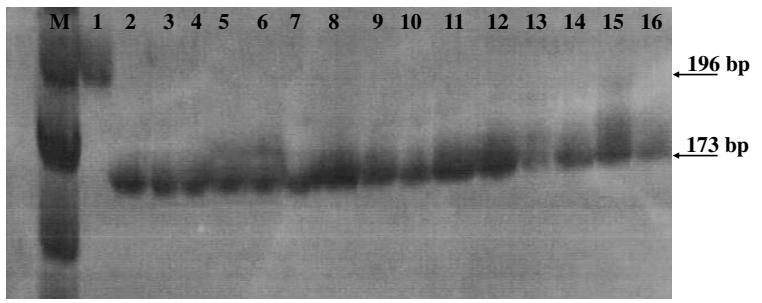

Fig. 4 Genotypic evaluation of $\mathrm{BC}_{2} \mathrm{~F}_{2}$ population using Glu_6 marker; $\mathrm{M}=$ Marker; 1 = Leum Pua; 2 = IR64; 3$16=\mathrm{BC}_{2} \mathrm{~F}_{2}$ individuals.

Table 1 The number of plants selected for aroma and black pericarp in $\mathrm{BC}_{1} \mathrm{~F}_{1}$ and $\mathrm{BC}_{2} \mathrm{~F}_{1}$ generations.

\begin{tabular}{lccc}
\hline Generation & No. progenies & \multicolumn{2}{c}{ Selection method } \\
\cline { 3 - 4 } & & Aromatic $^{1}$ & Black pericarp $^{2}$ \\
\hline $\mathrm{BC}_{1} \mathrm{~F}_{1}$ & 87 & 43 & 4 \\
$\mathrm{BC}_{2} \mathrm{~F}_{1}$ & 55 & 2 & 1 \\
\hline
\end{tabular}

1,2 indicate the sequence of stepwise selection procedure: the seedling and harvesting stages, respectively.

seedling stage, 43 individual plants heterozygous for aroma were selected. At harvesting stage only 4 black pericarp plants were observed. All the selected plants were backcrossed to IR64 variety to produce $\mathrm{BC}_{2} \mathrm{~F}_{1}$ population, and a total of 55 individual plants were obtained (Table 1).

From the $\mathrm{BC}_{2} \mathrm{~F}_{1}$ population, all individual plants were screened for aroma by using the Naro1 marker again targeting the heterozygous individuals. Two plants were selected for aroma whereas only 1 plant carrying black pericarp (Table 1).

\section{Foreground and background trait selection}

The background traits are non-glutinous and semidwarf. By selfing the selected $\mathrm{BC}_{2} \mathrm{~F}_{1}$ plants, a total of $46 \mathrm{BC}_{2} \mathrm{~F}_{2}$ individual plants were obtained. At seedling stage, MAS was employed to screen the homozygous individual plants for aroma and nonglutinous traits. All the 46 plants were screened for non-glutinous trait by using Glu_6 marker, and the result showed that all the $\overline{4} \overline{6}$ plants were non-glutinous. Only 13 plants however were homozygous for aroma carrying the Naro1 marker (Table 2).

In addition to MAS, phenotypic selection was also carried out in different backcross populations. The Naro1 marker showed 2 different amplified bands with the sizes of $236 \mathrm{bp}$ and $244 \mathrm{bp}$ to detect aromatic and non-aromatic alleles, respectively. The Glu_6 marker showed 2 different bands with sizes of
Table 2 The numbers of plants were selected for nonglutinous, aromatic, semi-dwarf and black pericarp in $\mathrm{BC}_{2} \mathrm{~F}_{2}$ generations.

\begin{tabular}{|c|c|c|c|c|c|}
\hline \multirow[t]{2}{*}{ Generation } & \multirow[t]{2}{*}{ No. } & \multicolumn{2}{|c|}{ MAS } & \multicolumn{2}{|c|}{ Phenotypic } \\
\hline & & Non-g ${ }^{1}$ & $\mathrm{Aro}^{2}$ & Sem- $d^{3}$ & Bla-p ${ }^{4}$ \\
\hline $\mathrm{BC}_{2} \mathrm{~F}_{2}$ & 46 & 46 & 13 & 13 & 6 \\
\hline
\end{tabular}

Table 3 The comparison of characteristic between parental and 6 selected lines.

\begin{tabular}{lcccc}
\hline Variety & \multicolumn{4}{c}{ Traits } \\
\cline { 2 - 5 } & $\begin{array}{c}\text { Plant } \\
\text { height }(\mathrm{cm})\end{array}$ & $\begin{array}{c}\text { Panicles } \\
\text { per plant }\end{array}$ & $\begin{array}{c}\text { Seeds per } \\
\text { panicle }\end{array}$ & $\begin{array}{c}\text { Yield per } \\
\text { plant (g) }\end{array}$ \\
\hline Leum Pua & $143 \pm 12$ & $12 \pm 2$ & $180 \pm 50$ & $11.2 \pm 4.8$ \\
IR64 & $87.2 \pm 3.4$ & $14.0 \pm 2.6$ & $162 \pm 26$ & $26.6 \pm 4.5$ \\
Line 1 & 95 & 9 & 190.33 & 19.97 \\
Line 2 & 109 & 6 & 161.33 & 19.93 \\
Line 3 & 98 & 15 & 144.00 & 19.89 \\
Line 4 & 97 & 7 & 160.33 & 12.27 \\
Line 5 & 91 & 4 & 105.67 & 11.76 \\
Line 6 & 97 & 14 & 149.89 & 10.44 \\
Mean & 93.66 & 7.35 & 137.90 & 10.71 \\
S.D. & 8.63 & 4.92 & 54.94 & 8.01 \\
\hline
\end{tabular}

$173 \mathrm{bp}$ and $196 \mathrm{bp}$ to detect non-glutinous and glutinous alleles, respectively. The heterozygous genotype exhibited both alleles in each marker. All the 13 plants which were identified to be homozygous of non-glutinous and aromatic by MAS in $\mathrm{BC}_{2} \mathrm{~F}_{2}$ were critically evaluated visually for black pericarp and semi-dwarf characteristics in the paddy field at harvesting stage. The evaluation confirmed that all the 13 plants were semi-dwarf. However, only 6 plants had seeds with black pericarp (Table 2).

\section{Comparison of parents and selected lines}

Comparison was made between the parents and the 6 improved (selected) lines for some agronomic characteristics (Table 3). The populations were on average $93.66 \mathrm{~cm}$ tall, had 7.35 panicles per plant, 137.90 seeds per panicle, and yield $10.71 \mathrm{~g}$ per plant (Table 3).

\section{DISCUSSION}

The Leum Pua black seeded rice variety has high anthocyanin content; it is soft, aromatic, and testy when cooked. As it is photoperiod sensitive, tall, and liable to lodging, gives low yield. In order to 
improve the yield, lodging resistance, and to convert its glutinous characteristics, backcross breeding was attempted by using IR64 as a recurrent and Leum Pua as a donor parent. Subsequently, $87 \mathrm{BC}_{1} \mathrm{~F}_{1}$ plants were developed and the individual plants were evaluated for improved yield, dwarfness and non-glutinous characteristics, while maintaining its black pericarp, and aroma by employing MAS together with phenotypic selection. The stepwise selection was carried out to save cost and time ${ }^{11}$.

At $\mathrm{BC}_{2} \mathrm{~F}_{2}$ stage, all the 46 plants screened for non-glutinous trait and aroma by using Glu_ 6 and Naro1 markers, as a result 13 plants were identified to be homozygous for non-glutinous and aroma. The MAS could perform the selection at seedling stage without the need to transplant the plantlet to the field ${ }^{9,10,12}$. The phenotypic evaluation confirmed that all the 13 plants were semi-dwarf and 6 plants had seeds with black pericarp.

The modified backcrossing using backcrossing following by pedigree selection could select lines superior to the parental lines. This can carry out the bonus trait especially yield potential. The 6 improved lines had intermediate height and number of panicles per plant as compared to the parents, but they had a higher number of seeds per panicle than the parents. This shows that the improved lines are also superior in yield to both parents.

At $\mathrm{BC}_{2} \mathrm{~F}_{2}$ generation, 6 improved lines were developed by using MAS together with phenotypic (visual) selection. This shows that MAS in conjunction with phenotypic (visual) selection will be effective and could accelerate the process of rice improvement. This method can be called alternative phenotypic and genotypic selection.

\section{Conclusions}

New rice lines carrying the non-glutinous and semidwarf traits from IR64 and the aromatic and black pericarp characteristics of Leum Pua and high yield potential than Leum Pua rice variety could be candidates for new rice lines for back pericarp, aromatic, semi-dwarf plant type.

Acknowledgements: This work was supported by Kasetsart University Research and Development Institute (KURDI), Kasetsart University. First author would like to thank the Centre for Advanced Studies for Agriculture and Food, Institute for Advanced Studies, Kasetsart University Under the Higher Education Research Promotion and National Research University Project of Thailand, Office of the Higher Education Commission, Ministry of Education, Thailand for providing partial fund for her research.

\section{REFERENCES}

1. Wang C, Shu Q (2007) Fine mapping and candidate gene analysis of purple pericarp gene $P b$ in rice (Oryza sativa L.). Chin Sci Bull 52, 3097-104.

2. Noenplab A, Noenplab ANL, Watjanaphum P, Sukseum P (2010) Leum Pua, a glutinous rice variety: genetic conservation for nutritional values. In: Proceedings of 2010 Northern Rice Research Center Annual Conference, Phitsanulok, pp 187-97.

3. Buttery RG, Ling LC, Juliano BO, Turnbaugh JG (1983) Cooked rice aroma and 2-acetyl-1-pyrroline. $J$ Agr Food Chem 31, 823-6.

4. Jin Q, Waters D, Cordeiro GM, Henry RJ, Reinke RF (2003) A single nucleotide polymorphism (SNP) marker linked to the fragrance gene in rice (Oryza sativa L.). Plant Sci 165, 359-64.

5. Hirano HY, Sano Y (1998) Enhancement of $W x$ gene expression and the accumulation of amylase in response to cool temperatures during seed development in rice. Plant Cell Physiol 39, 807-12.

6. Han L, Zhang HY, Xu PZ, Li Y, Wang XD, Wu XJ (2006) Genetic analysis and histological study of red seed in rice. Acta Genetica Sin 33, 559-64.

7. Monna L, Kitazawa N, Yoshino R, Suzuki J, Masuda H, Maehara Y, Tanji M, Sato M, Nasu S, Minobe Y (2002) Positional cloning of rice semi dwarfing gene, sd-1: Rice "Green Revolution Gene" encodes a mutant enzyme involved in gibberellin synthesis. DNA Res 9, 11-7.

8. Benbouza H, Jacquemin JM, Baudoin JP, Mergeai G (2006) Optimization of a reliable, fast, cheap, and sensitive silver staining method to detect SSR markers in polyacrylamide gels. Biotechnol Agron Soc Environ 10, 77-81.

9. Rattanapol P, Sripichitt P, Sreewongchai T (2011) Development of functional DNA marker specific to aromatic gene in rice. In Proceedings of 49th Kasetsart Univ Annual Conference, Bangkok, pp 574-80.

10. Wanchana $S$, Toojinda T, Tragoonrung S, Vanavichit A (2003) Duplicated coding sequence in the waxy allele of tropical glutinous rice (Oryza sativa L.). Plant Sci 165, 1193-9.

11. Sreewongchai T, Toojinda T, Thanintorn N, Kosawang C, Vanavichit A, Tharreau D, Sirithunya P (2010) Development of elite indica rice lines with wide spectrum of resistance to thai blast isolates by pyramiding multiple resistance QTLs. Plant Breed 129, 176-80.

12. Collard BCY, Jahufer MZZ, Brouwer JB, Pang ECK (2005) An introduction to markers, quantitative trait loci (QTL) mapping and marker-assisted selection for crop improvement: the basic concepts. Euphytica 142, 169-96. 